\title{
Polarization and Ideological Congruence between Parties and Supporters in Europe
}

\author{
Royce Carroll \\ University of Essex \\ r.carroll@essex.ac.uk \\ Hiroki Kubo \\ Meijigakuin University \\ hkubo@law.meijigakuin.ac.jp
}




\begin{abstract}
The relationship between parties and their supporters is central to democracy and ideological representation is among the most important of these linkages. We conduct an investigation of party-supporter congruence in Europe with emphasis on the measurement of ideology and focusing on the role of party system polarization, both as a direct factor in explaining congruence and in modifying the effects of voter sophistication. Understanding this relationship depends in part on how the ideology of parties and supporters is measured. We use Poole's Blackbox scaling to derive a measure of latent ideology from voter and expert responses to issue scale questions and compare this to a measure based on left-right perceptions. We then examine how variation in the proximity between party ideological positions and those of their supporters is affected by the polarization of the party system and how this relationship interacts with political sophistication. With the latent ideology measure, we find that polarization decreases party-supporter congruence but increases the effects of respondent education level on congruence. However, we do not find these relationships using the left-right perceptual measure. Our findings underscore important differences between perceptions of left-right labels and the ideological constraint underlying issue positions.
\end{abstract}




\section{Introduction}

Political parties are the primary vehicles for aggregating voters' interests in elections. Hence, the ideological linkage between parties and voters is central to the nature of political representation (Powell, 2000; Huber and Powell, 1994; Dalton and Anderson, 2011). A core question within this topic is how ideologically close politicians are to their voters. This line of inquiry dates back at least to Miller and Stokes (1963) and produced a long tradition of linking politicians and voters in the US (e.g. Gerber and Lewis 2004; Lewis and Tausanovitch 2015; Clinton 2006), in Europe (e.g. Klingemann et al. 2017) and beyond (e.g. Saiegh 2015).

This voter-elite congruence may be distorted by a variety of factors at the individual, party and system levels. This can include voters lacking the knowledge to align with like-minded politicians (Jessee, 2010; Lachat, 2008; Kroh, 2009) or politicians failing to represent those voters (Klingemann et al., 2017; Canes-Wrone et al., 2002; Rogers, 2017). Both these factors being party-supporter incongruence can be affected by party polarization - the ideological dispersion of parties within the party system (McCarty et al., 2006; Lachat, 2008). On the one hand, polarization may directly result in parties being dealigned from their supporters (Hill and Tausanovitch, 2015; Fiorina and Levendusky, 2006). On the other hand, party polarization provides clarity to party representation by establishing clearer, more distinct reputations to which voters may respond (Levendusky, 2010; Hetherington, 2001).

How can we determine the degree of alignment between parties and voters? A key methodological concern in assessing ideological congruence is what constitutes ideology. As Poole (2005) notes, individuals' views on various policies tend to be related to an underlying tendency, or "constraint" (Converse, 1964). These relationships need not be based on substantive relationships among issues but rather may reflect a packaging of policies by elites. This underlying ideology can be seen as a psychological space that predicts 
the response to stimuli, such as roll-call votes or survey questions. These preferences are therefore spatial and, at least for elites, can be relatively low-dimensional (Poole, 2005).

Because of this, scholars studying mass-elite linkages often assume that ideological positions can be captured by the symbolic concepts of "left" and "right." That is, if individuals are aware of a "main" underlying dimension of political positions, they can perceive their location and that of political parties on a single conceptual scale. While leftright labels are a spatial analogy, these placements rely on the assumption that individuals compress the relevant policy space into these concepts. Moreover, these labels depend both on voters' capacity to make use of this information (Palfrey and Poole, 1987) and on their subjective notion of how these labels correspond to the ideological information they have about themselves and parties (Aldrich and McKelvey, 1977; Brady, 1985). In short, voters differ in their use, understanding and definition of these labels.

The distinction between the notion of ideology as a constraint that binds together disparate policy choices versus a scale based on symbolic labels is an important one. The process that "maps" issues into latent preference space is likely to differ from that which produces self and party perceptions on a symbolic left-right scale (Ansolabehere et al., 2008). The idea of policy or ideological distance as a latent quality of attitudes or as a symbolic label is therefore important to the concepts of party and voter policy locations. In turn, this distinction is pertinent to the mechanism behind how party polarization could increase or decrease the distance between parties and voters. Further, it affects how party polarization would influence the relationship between political sophistication and the assessment of ideological distances.

Here, we examine this measurement distinction in the context of parties' congruence with their voters, how it is affected by party polarization, and how polarization influences the effect of political sophistication on party-supporter alignment. To place parties and voters on a common scale, we take advantage of the features of the 2014 European Election Study (EES), which includes a set of issue questions corresponding to an expert survey of 
party positions as well as left-right self and party placements. We apply these measures to the question of whether party polarization - the overall dispersion of party positionsmitigates or exacerbates the ideological gap between parties and their supporters. We use a latent measure based on several issue scales in the EES and Chapel Hill Expert Survey (CHES) (Bakker et al., 2015) to examine how party polarization affects the ideological gap between party supporters and their preferred parties. We examine first the direct impact of polarization on the distance between voters and parties in a system and, second, how polarization modifies the effect of individual sophistication on party-supporter congruence. We then compare each of these findings to a measure based on left-right party and selfperceptions, which also aims to place parties and supporters on a comparable scale.

In the process, this study contributes to our understanding of the importance of measurement when using survey data for research questions on ideology. First, we exploit Keith Poole's Blackbox scaling method (Poole, 1998; Poole et al., 2016) to integrate voter self-placements with expert party placements on common issues and derive jointly-scaled latent positions. We compare this to an alternative approach based on left-right perception. For this, we make use of Aldrich-McKelvey Scaling (Aldrich and McKelvey, 1977), following Palfrey and Poole (1987), to put self- and party- left-right placements on a common scale that adjusts for certain forms of perceptual bias.

We argue that the distinction between a latent policy space and a left-right perceptual notion of representation is conceptually important for the study of both ideological congruence and polarization. Moreover, these measures result in different observed empirical patterns with regard to the role that polarization plays in distorting such party-supporter alignments and in mediating the effect of political sophistication. In particular, we find that polarization diminishes congruence while enhancing the importance of sophistication when positions are based on the latent ideology measure. Meanwhile, we observe different or even opposite patterns when measuring ideology via the left-right measure. The differences between the two measures are highly consequential for the meaning of polarization 
and congruence, and thus for the relationship between these quantities and with political sophistication.

\section{Congruence between Politicians and Citizens and Party Polarization: Literature and Expectations}

Since the classic work of Miller and Stokes (1963) on constituency-legislator representation, many studies have empirically examined how parties and politicians represent voters' preferences focusing on the context of congruence between politicians and voters. In European democracies, a large literature deals with individual party-voter linkages and directly assesses congruence between parties and their voters on a left-right spectrum (Boonen et al., 2017; Klingemann et al., 2017; Thomassen, 2005; Klingemann, 2009; Dalton et al., 2011; Carlin et al., 2015). Understanding congruence between parties and their supporters is important not only because it is related to whether parties serve as vehicles for policy representation, but also because it is closely linked to the question of whether voting behavior is based on ideological proximity (Merrill and Grofman, 1999; Adams et al., 2005). Naturally, an important theme in much of this literature is obtaining comparable estimates of voters' and elites' policy positions (Lewis and Tausanovitch, 2015; Tausanovitch and Warshaw, 2013; Lo et al., 2014).

The literature on both US and European party representation varies with regard to how polarization influences representation, suggesting that party polarization can conceivably both distort and enhance party-voter congruence. Several works on the topic of party congruence have emphasized the important role polarization plays in representation. An extensive US literature examines elite polarization in the US Congress (Poole and Rosenthal, 2011; McCarty et al., 2006) and much has argued there are likely to be a series of distorting effects for representation in general (Lee, 2015; Ansolabehere et al., 
2006; Bafumi and Herron, 2010; Mann and Ornstein, 2013) and for voter-elite congruence in particular (Hill and Tausanovitch, 2015; Fiorina and Levendusky, 2006). Comparative literature also envisions that party polarization could reduce the broader proximity between voters and politicians. Often this is implicit in studies of the origins of polarization (Ezrow, 2008; Dow, 2011; Curini and Hino, 2012) but is also suggested in the related contexts of overall government congruence (Powell, 2011) or proximity voting (PardosPrado and Dinas, 2010). Following this line of reasoning, we would expect that political polarization will widen the gap between party ideological positions and party supporters' positions.

However, other work on elite-voter alignment in the US, notably Levendusky (2010) and Ensley (2007), suggests that party polarization can enable voters to better use ideological cues by clarifying party positions. Similarly, in comparative contexts, a number of works suggest that polarization can enhance the ideological nature of voting decisions (Alvarez and Nagler, 2004; Dalton, 2008; Lupu, 2014) and specifically that polarization could enhance the clarity of information available to voters (Knutsen and Kumlin, 2005; Carroll and Kubo, 2018). Along these lines, Lachat (2008) has shown that party polarization tends to increase the degree of ideological voting. If party polarization results in voters with information to vote in a more ideologically consistent way (Levendusky, 2010), this effect would imply a stronger congruence between parties and supporters. By this reasoning, we would expect that political polarization will reduce the gap between party ideological positions and party supporters' positions.

In any context where voters make choices, behavior is likely to be conditioned on individual characteristics influencing variation in their ability to obtain and use information. Chief among these factors in literature on voting and mass opinion is political sophistication, often associated with educational attainment (Luskin, 1987, 1990; Delli Carpini and Keeter, 1996; Goren, 2004; Gordon and Segura, 1997). More sophisticated voters may, for example, be better able to identify differences between parties. A higher level of political 
sophistication, often measured empirically as education level, should enable voters to better identify the ideological location of party positions when aiming to support proximate parties (Boonen et al., 2017). In line with this traditional view, we therefore would expect that low levels of education will widen the gap between party ideological positions and party supporters' positions.

The informational effects of polarization depend in part on how party ideological positions serve as "shortcuts" (Popkin, 1994; Delli Carpini and Keeter, 1996; Lupia and McCubbins, 1998). If polarization serves the purpose of clarifying party positions, making it easier for less sophisticated voters to identify party locations, we would expect that party polarization will reduce the importance of political sophistication on party-supporter congruence.

Alternatively, Lau and Redlawsk (2001) indicate that partisanship and ideological labels depend on political sophistication to function as heuristics that enhance voters' decision-making process. If greater separation improves the heuristic functions of party labels, more sophisticated voters may be better able to use them and therefore may exhibit stronger ideological voting (Lachat, 2008), contributing to greater congruence. Therefore, by this reasoning, we would expect that party polarization will increase the effects of political sophistication on party-supporter congruence.

\section{Research Design}

\subsection{Measuring Ideological Linkages between Parties and Voters}

To study party-supporter ideological linkages, we must obtain measures allowing us to compare the ideology of parties and their supporters. Many variations exist in how to calculate both polarization and congruence from a given ideology measure (Maoz and Somer-Topcu, 2010; Golder and Ferland, 2017; Andeweg, 2011). Our concern here is 
primarily with the measurement of ideology itself, particularly the empirical task of recovering an ideological measure to compare parties and voters.

For our emphasis, we focus on two measures that can capture both voter and party ideology within a party system, and thus can be applied to measure both polarization and congruence. ${ }^{1}$ The first measure attempts to capture the latent ideology derived from issue scales and compare jointly-scaled respondent and party locations. We contrast this with the very different notion of ideological location using respondent left-right placements of parties and voters. For left-right placements, we attempt to address the problem of differences between voters in the perception of these labels.

These two concepts correspond roughly to substantive and symbolic notions of ideology, respectively (Ellis and Stimson, 2009, 2012). The latent ideology measure is defined as the ideology in terms of the aggregate meaning of attitudes on narrower policy questions, in which voters place themselves and experts place parties on issue scales. This approach has the most in common with measures using elite voting behavior to derive latent ideology (Poole, 2005; Poole and Rosenthal, 1997). By contrast, the left-right perceptions measure is defined as how voters perceive party positions and their own locations in an abstract left-right spectrum. We next elaborate on this distinction.

\subsubsection{Perceptual Left-Right versus Latent Ideological Positions}

The meaning of "ideology" is ambiguous (Conover and Feldman, 1981; Feldman, 1988), with many possible conceptualizations and definitions. We focus on two concepts of ideology. First, we consider a symbolic notion of ideology as the perception of the concepts of "left" and "right" by voters. Although the meaning of left-right varies across countries,

\footnotetext{
${ }^{1}$ Note that the scope of this paper is limited to measures developed in the work of Keith Poole, and is not therefore intended to addresses the wide array of possible measures for these purposes. This includes those with similar aims based on MP representation (Belchior et al., 2016; Belchior, 2013), as well as a vast array of other measures that focus on some aspect of either polarization or congruence (e.g. Clark and Leiter 2014; Dalton 2006; Maoz and Somer-Topcu 2010; Rehm and Reilly 2010; Pardos-Prado and Dinas 2010; Ferland 2018; Klingemann et al. 2017)
} 
voters generally use ideological labels as heuristics to simplify complex political information into a single "left-right" axis. These types of labels exist across most party systems because they are a useful way to comprehend and organize relationships among parties and the movements of policy (Knutsen, 1998, 1995). Left-right language in political systems reduces the practical complexity of political choices and political communications (Fuchs and Klingemann, 1989) and provides a link between parties and voters. While the content will vary widely across political systems (Huber and Inglehart, 1995), these terms often can absorb a range of substantive conflicts as issue cleavages emerge. In surveys, respondents are often asked to locate themselves and parties on the left-right spectrum. While these perceptions are subjective judgments, a bias-adjusted version of such measures provides an informative basis for a symbolic form of party-supporter linkage (Aldrich and McKelvey, 1977)

However, the symbols associated with left and right do not necessarily account for the substantive distinctions revealed by policy issues. Concrete policy concepts may give voters a clearer idea of where they stand in operational terms on matters of basic economic and social policies. Political systems tend to aggregate information about party policy positions into a basic underlying policy space. In this way, we can also define ideology as the latent aggregated information seen across differences on policy issues - the constraint that bundles together issues (Poole, 2005). We can measure overall policy positions by using a scaling approach to identify the latent tendencies exhibited by the issues positions.

In what follows, we describe how measures of the party policy positions and partisans' ideology can be obtained following these "left-right perceptual" and "latent ideology" concepts of policy positions.

\subsubsection{Measuring Latent Ideology}

To capture latent ideology, we take a joint scaling approach to link measures of party locations on issue scales (here, placed by experts) and voter responses on equivalent issues. 
Related approaches have been fruitful in numerous settings (Hill and Tausanovitch, 2015; Tausanovitch and Warshaw, 2014; Lewis and Tausanovitch, 2015). Here we analyze mass survey data from EES and an expert survey data from CHES to recover a common policy space between voters and parties. There are unique advantages of EES 2014 and CHES 2014 for this purpose. Both of these questionnaires are organized to be consistent across nations and, most importantly for current purposes, there are questions included in each that are designed to be comparable between EES voters' responses and CHES experts' judgements. The approach we take here uncovers the basic space underlying this set of policy issues.

We unite the expert and voter responses on seven EES questions: economic intervention, redistribution, government spending, civil liberties, immigration, EU integration and environment issues to recover a common policy space. ${ }^{2}$

We use Poole's Blackbox scaling technique to uncover the basic policy space contained within the issue scales of elite survey data (Poole, 1998; Poole et al., 2013; Armstrong et al., 2014; Poole et al., 2016). Poole (1998) developed the Blackbox scaling procedure specifically to directly estimate ideal points on the main latent dimensions of variance present in a series of issues scale questions. Furthermore, by applying this method to the policy issues that are shared across the two surveys, we can recover a common ideological space among the respondents-in this case, the parties and voters within the survey.

We recover all of the individual voters' and parties' (the expert judgments) ideal points by reducing survey data matrix to its basic dimensions. We decompose the original survey

\footnotetext{
${ }^{2}$ See the Tables 3 and 4 in the Appendix for details. Although eight issues are recorded in each survey, a general question on lifestyle issues in the CHES lacks a sufficiently similar corresponding question within the EES, which refers to the specific matter of same-sex marriage. We otherwise erred on the side of including the remaining 11-point scale issue questions, but due to a relatively weak comparability between the EES EU control and CHES Nationalism questions, we instead use a rescaled version of the CHES 7-point EU Position variable because of its greater similarity to the EES question. However, we found similar results to those presented here when using the CHES Nationalism question. More generally, we note that choosing among various subsets of questions would certainly produce a variety of different results and these sensitivities are an area for future research. See the Appendix for a discussion of the face validity of the estimates.
} 
data matrix on the seven issues to derive the ideal points. As described by Poole (1998), Blackbox begins with a survey data matrix $X$, containing the $i$ th individual respondent's $(i=1, \ldots, n)$ reported policy position on the $j$ th issue. Blackbox decomposes the matrix to individual respondents' true coordinates $(\Psi)$ multiplied by a matrix of weights $(W)$, an intercept term $(c)$ and an error term $(E)$ as follows: $X=\left[\Psi W+J_{n} c\right]+E$. The coordinates of individual respondents are obtained by solving this equation, where $\Psi_{i k}$ is the $i$ th individual's position on the $k$ th dimension. Below, we use the first dimension of this scaling output and refer to this measure below as "latent ideology." The party locations are the means of the scaled expert placement locations for each party.

\subsubsection{Measuring Perceptual Left-Right Positions}

To capture perceptual left-right ideology, we analyze the voters' self-reported ideology and party placement as measured in the EES survey. ${ }^{3}$ Left-right self and party placements contain information about how voters perceive themselves and party positions in a symbolic left-right spectrum. Though this is often used in raw form, we do not use these data directly. An important methodological issue in interpreting left-right placements is the problem of differential item functioning (DIF) errors - the biases in perception held by each respondent concerning the left-right concept (Brady, 1985, 1989). For example, extreme voters may place themselves closer to the center, while placing most parties to one side. We follow Palfrey and Poole (1987) and use Aldrich-McKelvey Scaling (Aldrich and McKelvey, 1977), which is designed to recover a common scale of voters and parties within given survey that accounts to some extent for the DIF bias in left-right placement of party positions and produces a set of adjusted ideal points for survey respondents

\footnotetext{
${ }^{3}$ We analyze the following questions in EES 2014. "QPP13: In political matters people talk of "the left" and "the right". What is your position? Please use a scale from 0 to 10 , where '0' means "left" and '10' means "right". Which number best describes your position?" "QPP14: And about where would you place the following political parties on this scale? How about the...? Which number from 0 to 10 , where '0' means "left" and '10' means "right" best describes this party?'
} 
(Palfrey and Poole, 1987; Armstrong et al., 2014; Poole et al., 2016). ${ }^{4}$

Using voter data on left-right placement, this approach decomposes observed survey data into party stimuli and voters' distortion parameters. We analyze a survey data matrix of voters' left-right placement of party positions from the EES data which enables us to obtain "true" positions for party stimuli as well as individual perceptual bias parameters. Aldrich-McKelvey scaling uses the relationship between individual self-placements on a left-right scale and common stimuli (parties, politicians) on the same scale to adjust for the perceptual bias that occurs due to one's own positional perspective. This involves estimating positions for common stimuli, calculating individual perceptual distortion, and adjusting individual left-right self-placements. As described by Poole et al. (2016), this approach treats voters' reported left-right positions $z_{i j}$ as a linear function of these "true" stimuli positions $\left(\zeta_{j}\right)$ and error term $\left(\mu_{i j}\right)$, as follows: $z_{i j}=\alpha_{i}+\beta_{i} \zeta_{j}+\mu_{i j}$. The intercept term $\left(\alpha_{i}\right)$ indicates the extent to which respondents tend to bias their party positions rightward or leftward. The weight term $\left(\beta_{i}\right)$ captures voters' capacity to recognize party positions overall.

Correcting for bias using these parameters results in estimates for both stimuli locations (parties) and respondents (voters) that can be compared within each survey.

\footnotetext{
${ }^{4}$ Note that below we use the MLE implementation of Aldrich-McKelvey scaling described by Poole et al. (2016). While this results in losing observations from respondents with some missing stimuli responses, it has an advantage for current purposes in that it requires no assumptions about the location of the estimated stimuli locations (cf. Hare et al. 2015), which we rely on for both the congruence and polarization measures. Although we retain these observations in the sample presented below using the latent ideology measure, we find similar results on key variables for that analysis when the sample is restricted to those without missing values on the left-right perceptual measure. Note that we also remove 14 additional observations that produce extreme values outside of the proper range of the AldrichMcKelvey estimates.
} 


\subsection{Dependent Variable}

Our dependent variable is the distance between parties and supporters ${ }^{5}$ on each of the measures described above. To view this distance more closely between the two measures, we isolate the specific example of the Netherlands. Figure 1 displays a box plot of the distribution of the supporters of each party in the system, with points indicating the locations of their parties. Each measure reproduces a roughly similar ordering of the parties and their supporters, albeit with some disagreements. Yet, each provides quite different locations for parties and voters in relative terms, with the appearance of greater congruence overall in the left-right measure. This baseline distinction is not surprising given that the left-right measure is derived from voter's own perceptions, rather than expert placements. ${ }^{6}$

Since our concern in this study is the relationship between parties and voters, we calculate the absolute value of the ideological difference between the above-estimated party positions and the median ideology of party supporters-defined as the party for which the respondent reports being closest to. We consider this value as the ideological representation gap between parties, where smaller values represent a closer alignment between parties and supporters. Thus, higher values in the analysis below imply less party-supporter congruence. We calculate the value of the ideological gap between parties and supporters for parties in the 28 countries in EES $2014 .^{7}$ Since the results of this absolute value calculation are highly skewed, we transform this quantity by taking the square root and use a linear model below on the resulting variable.

We standardize the range of the left-right perceptual measure by subtracting the coun-

\footnotetext{
${ }^{5}$ The the parties associated with supporters are based on EES question pp21, which reads"Do you consider yourself to be close to any particular political party?"

${ }^{6}$ Indeed many of the differences in the findings presented here are also likely to be directly related to the use of perceived versus expert positions for party locations between the measures.

${ }^{7}$ The total number of respondents with information on party support is 15,341, 1,771 of which are unable to produce measures on either dependent variable due to missing data on issue or party placements. We also remove parties that have less than 5 usable supporter observations in the survey.
} 

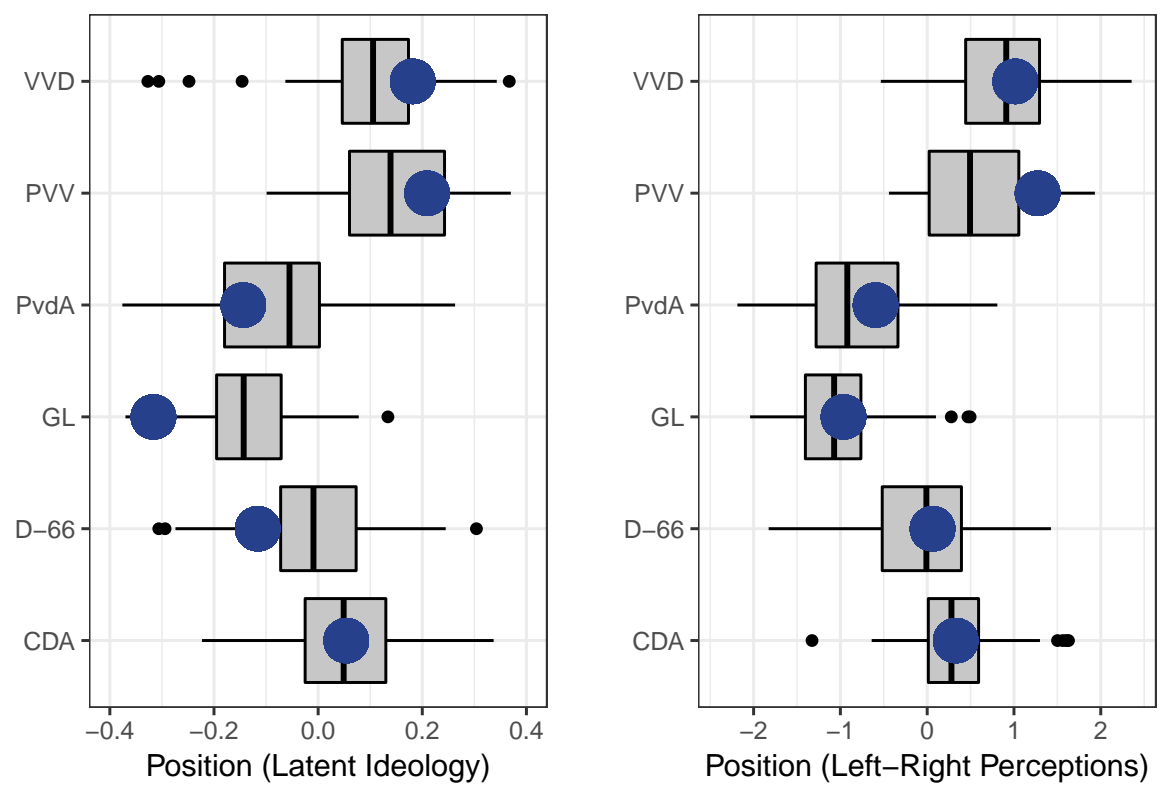

Figure 1: Example Party Locations and Voter Distributions in The Netherlands

Notes: VVD: People's Party for Freedom and Democracy, PVV: Party for Freedom, PvdA: Labour Party, GL: GreenLeft, D-66: Democrats 66, CDA: Christian Democratic Appeal. Boxes represent distributions of supporters' positions. Points indicate party positions.

try mean and dividing it by the standard deviation of the individual ideal point scores within the survey. This ensures that the variation in party-supporter congruence is not determined by the scale differences across countries in this measure. ${ }^{8}$

\subsection{Independent Variables}

Our concern here is how polarization and individual sophistication affect party-supporter ideological alignment. For a measurement of political sophistication, we use the education level of the respondent indicated in the EES. The notion of political sophistication is often treated as correlated with, and therefore proxied by, measures of educational attainment

\footnotetext{
${ }^{8}$ While the latent ideology measure establishes a comparable scale across countries via joint-scaling of all countries, the scores from the left-right perceptual measure are generated country-by-country. These data lack common stimuli across countries necessary to directly establish a cross-country common scale via Aldrich-McKelvey scaling. Without standardizing the range of the ideal points in the system in the left-right perceptual measure, surveys producing a wider absolute range of ideal points would appear to have both larger party polarization and larger voter-party gaps, resulting in correlations as an artifact of the scale differences.
} 
(Neuman, 1986; Luskin, 1987, 1990; Delli Carpini and Keeter, 1996; Mondak, 1999; Goren, 2004; Highton, 2009). We make a binary variable for education level, which is designed to standardize and simplify the education measure across cases. This binary variable represents 'high' and 'low' education within each country-year, with those who are equal or greater than the country median education level coded as 1 , and others coded 0 .

We also control for the party location on the measure in question due to the possibility that party-supporter linkages may differ systematically between parties with left and right positions. Similarly, we include the location of the respondent on the same measure to control for any differences between voters on the left and right. Finally, we control for the vote share of the respondent's supported party, as reported in the CHES data.

\section{Results}

We use a multi-level linear model with country-level and party-level random effects. Table 1 shows the results of multi-level regression analysis for the latent variable measure. The results of the analysis using the left-right perceptual measure are shown in Table 2. In each table, we examine the individual-level education level variable, Education, as well as the individual-, party- and country-level control variables described above. In the second model for each dependent variable, we include the interaction between country-level party polarization and the respondent's education level.

With regard to the latent ideology measure, party polarization increases the distance between voters and parties. Predicted values from the first model in Table 1 are shown in the left side of Figure 2. Our political sophistication measure, Education Level, also correlates with larger party-supporter distances, as expected. Less educated voters have larger ideological distances with the parties they support. This tendency, however, is exacerbated by polarized environments, as shown in Model 2. In fact, in the least polarized environments, there is no effect for education in improving party-supporter alignment. 
This is illustrated in the plot on the left side of Figure 3, which shows that the reductive effect of education is present only at higher levels of polarization. In sum, the results from the latent ideology measure indicate that when parties are more dispersed on the main latent dimension of ideology, this comes at the expense of congruence and increases the disparities between less and more sophisticated voters. These results are consistent with arguments suggesting that more sophisticated voters are advantaged in more polarized environments.

With the left-right perceptual measure, shown in Table 2, we again find that education level reduces party-supporter distances as we would expect. However, we find a very different pattern with regard to other variables. When the left-right perceptual measure is used, party polarization appears to be related to stronger party-supporter congruence. The predicted values of this effect are as shown in the plot on the right side of Figure 2. The left-right perceptual measure produces results consistent with the arguments about party polarization facilitating voters ability to identify and support ideologically proximate parties. Furthermore, the conditional effects for education just shown for the latent measure are not observed using the left-right ideology measure. As in the results using the latent ideological measure, education does decrease party-supporter distances in general. However, as shown in the right side of Figure 3, a weak conditional effect exists in the opposite direction. With regard to left-right polarization, the effect of education reducing party-supporter incongruence is present only under conditions of low left-right party polarization.

This finding is more consistent with suggestions that sophistication is more important when parties are less clearly differentiated and provide less clear information. Taken together, the results from the left-right perceptual measure indicate that party differentiation in perceived left-right labels both improves congruence and reduces the disparities between less and more sophisticated voters.

Also noteworthy are the different effects of two of the control variables. Party posi- 
tion has an opposite effect with each measure, with the right-wing parties having higher congruence when the latent ideology measure is used and left-wing parties having higher congruence when using the left-right perceptual measure. The respondent's own estimated position also correlates with gaps with their parties differently for each measure. Respondents with positions further to the right have larger distances from the parties they support on the latent ideology measure, but have smaller distances in the left-right perceptual measure. 
Table 1: Regression results for Latent Ideology Measure

\begin{tabular}{lcc}
\hline \hline DV=Party-Supporter Distance & $(1)$ & $(2)$ \\
\hline Party Polarization & $.3505^{* *}$ & $.4035^{* * *}$ \\
& $(.1107)$ & $(.1121)$ \\
Education & $-.0101^{* * *}$ & .0112 \\
& $(.0026)$ & $(.0088)$ \\
Education $\times$ Party Polarization & & $-.1358^{*}$ \\
& & $(.0535)$ \\
Party Position & $-.1515^{* * *}$ & $-.1521^{* * *}$ \\
& $(.0304)$ & $(.0304)$ \\
Voter Position & $.2455^{* * *}$ & $.2447^{* * *}$ \\
& $(.0091)$ & $(.0091)$ \\
Party Vote Share & $-.0011^{*}$ & $-.0011^{*}$ \\
& $(.0005)$ & $(.0005)$ \\
Constant & $.3181^{* * *}$ & $.3097^{* * *}$ \\
& $(.0200)$ & $(.0202)$ \\
\hline \hline No. Individuals & 12294 & 12294 \\
No. Parties & 187 & 187 \\
No. Countries & 28 & 28 \\
log(likelihood) & 7383.52 & 7386.74 \\
\hline \hline
\end{tabular}

Standard errors in parentheses

${ }^{+} p<0.10,{ }^{*} p<0.05,{ }^{* *} p<0.01,{ }^{* * *} p<0.001$ 
Table 2: Regression results for Left-Right Perception Measure

\begin{tabular}{|c|c|c|}
\hline 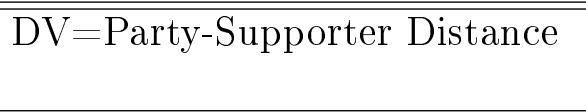 & (1) & $(2)$ \\
\hline Party Polarization & $\begin{array}{c}-.1694^{* *} \\
(.0625)\end{array}$ & $\begin{array}{c}-.2135^{* *} \\
(.0659)\end{array}$ \\
\hline Education & $\begin{array}{c}-.0186^{* *} \\
(.0068)\end{array}$ & $\begin{array}{l}-.1128^{*} \\
(.0473)\end{array}$ \\
\hline Education $\times$ Party Polarization & & $\begin{array}{l}.1126^{*} \\
(.0560)\end{array}$ \\
\hline Party Position & $\begin{array}{c}.0408^{* * *} \\
(.0084)\end{array}$ & $\begin{array}{l}.0409^{* * *} \\
(.0084)\end{array}$ \\
\hline Voter Position & $\begin{array}{c}-.0501^{* * *} \\
(.0047)\end{array}$ & $\begin{array}{c}-.0502^{* * *} \\
(.0047)\end{array}$ \\
\hline Party Vote Share & $\begin{array}{c}.0002 \\
(.0005)\end{array}$ & $\begin{array}{c}.0002 \\
(.0005)\end{array}$ \\
\hline Constant & $\begin{array}{l}.8139^{* * *} \\
(.0529) \\
\end{array}$ & $\begin{array}{c}.8515^{* * *} \\
(.0558) \\
\end{array}$ \\
\hline No. Individuals & 8331 & 8331 \\
\hline No. Parties & 168 & 168 \\
\hline No. Countries & 28 & 28 \\
\hline $\log ($ likelihood $)$ & -1448.13 & -1446.11 \\
\hline
\end{tabular}



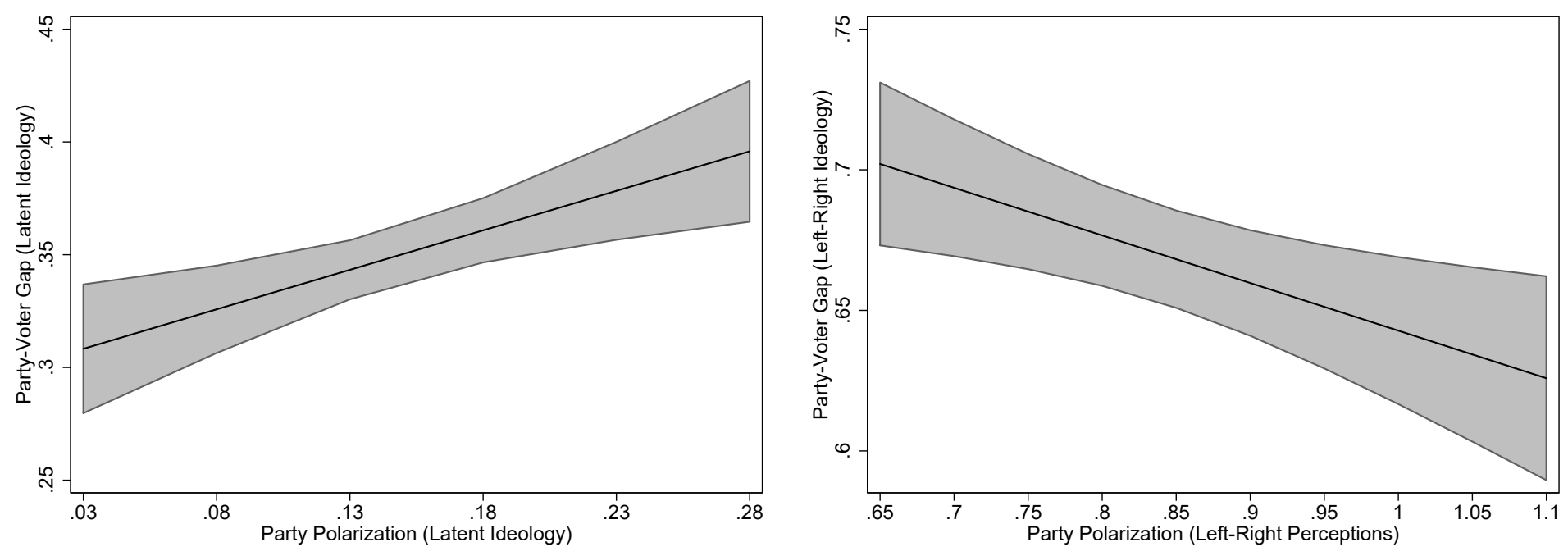

Figure 2: Predicted Party-Supporter gap, by Party Polarization

\section{Discussion}

Here, we have investigated the influence of ideology measures on uncovering the relationship between party polarization and party-supporter ideological congruence. As Poole (2005) notes, issue positions are bound by a constraint that can be uncovered as a latent property across choices. The nature of this constraint is often thought to be captured by direct measures of left-right perceptions. That is, such data is typically interpreted as capturing the most important differences in spatial locations. In this study, we recover a latent common ideological space for European voters and parties from voter and expert issue responses using Poole's Blackbox scaling (Poole, 1998; Poole et al., 2016). This latent ideology measure enables us to examine correlates of distances between voters and parties. We contrast this with a measure derived from respondents' left-right self and party placements. For the left-right perceptual measure, we use Aldrich-McKelvey scaling (Aldrich and McKelvey, 1977; Palfrey and Poole, 1987) to adjust for bias in these placement data. 

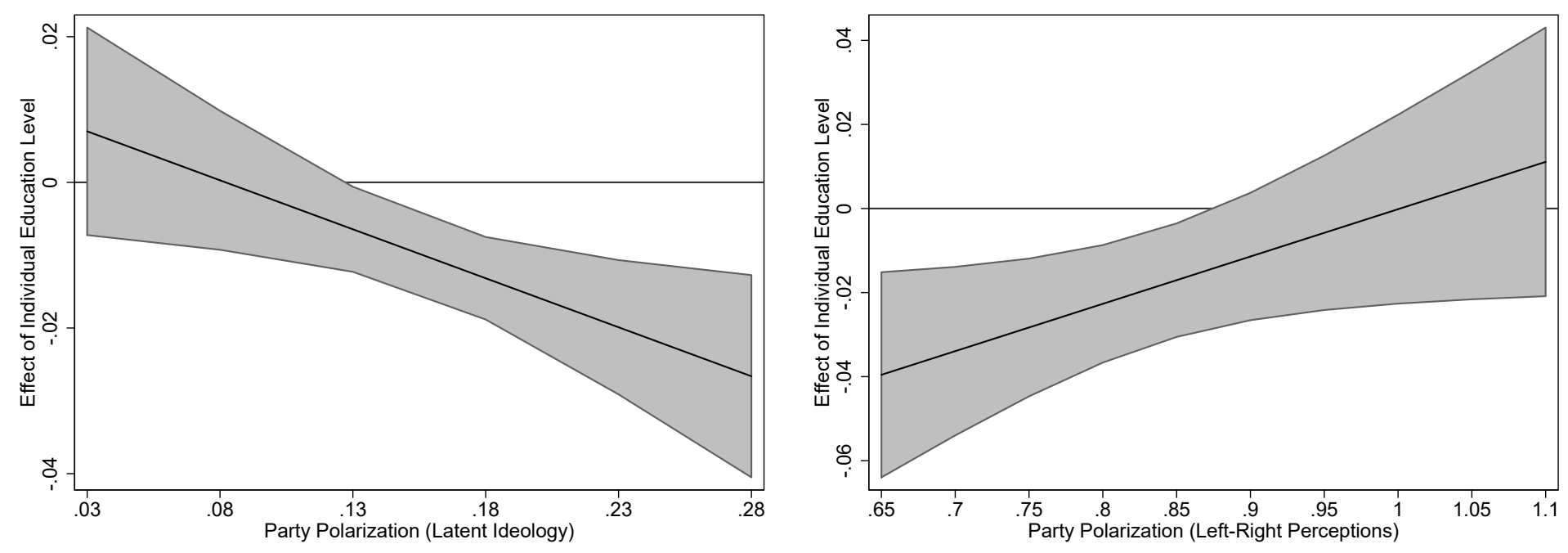

Figure 3: Marginal effects of Education Level on Party-Supporter gap, by Party Polarization

The choice between measures has significant implications for the interpretation of the relationship between party system polarization and voter-party linkages. Each measure of ideological location we employ here is intuitive, grounded in existing work, and appears to be face-valid. Yet, our results suggest that understanding the ideological proximity between voters and parties depends on, among other things, how we define and measure ideology.

While this study conducts only a limited analysis of possible variants in measurement, ${ }^{9}$ our results indicate that the relationship between party polarization and party-supporter congruence is sensitive to the measurement of ideology, as is how polarization interacts with political sophistication. The direct effects of polarization and interactive effects we find for education when using our latent ideology measure are not present when using the perceptual left-right measure. Such disparate findings suggest that these seemingly similar but fundamentally different notions of ideology have a substantial impact on the conclusions we can draw regarding concepts of party polarization and party-supporter

\footnotetext{
${ }^{9} \mathrm{~A}$ variety of further combinations we do not explore here would certainly yield even more variation in results such as this. We also avoid important and widely-discussed questions of how congruence and polarization should be calculated when using any underlying measure of ideological positions.
} 
distances.

In particular, we note that the latent ideology approach based on issue scales provides a useful measure for understanding representation that has much in common conceptually with the measures of elite locations used in other elite studies that reflect the ideological constraint revealed across multiple stimuli responses (Poole, 2005; Carroll and Poole, 2014). Our findings also have a bearing more generally on how we should interpret measures based on left-right placements.

Our results are limited only to a single survey and a comparison of just two measures. However, they suggest the need for more research into the importance of measurement in studies of ideological positions in party politics. To the extent latent policy space is of interest to future work on this topic, it will be important to establish more common issue questions between surveys of mass and elite preferences. 


\section{References}

Adams, J. F., Merrill III, S., and Grofman, B. (2005). A unified theory of party competition: a cross-national analysis integrating spatial and behavioral factors. Cambridge University Press.

Aldrich, J. H. and McKelvey, R. D. (1977). A method of scaling with applications to the 1968 and 1972 presidential elections. The American Political Science Review, pages 111-130.

Alvarez, R. M. and Nagler, J. (2004). Party system compactness: Measurement and consequences. Political Analysis, 12(1):46-62.

Andeweg, R. B. (2011). Approaching perfect policy congruence: Measurement, development, and relevance for political representation. How democracy works: Political representation and policy congruence in modern societies, pages 39-52.

Ansolabehere, S., Rodden, J., and Snyder, J. M. (2006). Purple america. The Journal of Economic Perspectives, 20(2):97-118.

Ansolabehere, S., Rodden, J., and Snyder, J. M. (2008). The strength of issues: Using multiple measures to gauge preference stability, ideological constraint, and issue voting. American Political Science Review, 102(02):215-232.

Armstrong, D. A., Bakker, R., Carroll, R., Hare, C., Poole, K. T., Rosenthal, H., et al. (2014). Analyzing spatial models of choice and judgment with R. CRC Press.

Bafumi, J. and Herron, M. C. (2010). Leapfrog representation and extremism: A study of American voters and their members in Congress. American Political Science Review, $104(3): 519-542$.

Bakker, R., De Vries, C., Edwards, E., Hooghe, L., Jolly, S., Marks, G., Polk, J., Rovny, J., Steenbergen, M., and Vachudova, M. A. (2015). Measuring party positions in europe the chapel hill expert survey trend file, 1999-2010. Party Politics, 21(1):143-152.

Belchior, A. M. (2013). Explaining left-right party congruence across European party systems: a test of micro-, meso-, and macro-level models. Comparative Political Studies, $46(3): 352-386$.

Belchior, A. M., Tsatsanis, E., and Teixeira, C. P. (2016). Representation in times of crisis: deputy-voter congruence on views of representation in Portugal. International Political Science Review, 37(2):277-293.

Boonen, J., Pedersen, E. F., and Hooghe, M. (2017). The effect of political sophistication and party identification on voter-party congruence. A comparative analysis of 30 countries. Journal of Elections, Public Opinion and Parties, 27(3):311-329. 
Brady, H. E. (1985). The perils of survey research: Inter-personally incomparable responses. Political Methodology, 11(3/4):269-291.

Brady, H. E. (1989). Factor and ideal point analysis for interpersonally incomparable data. Psychometrika, 54(2):181-202.

Canes-Wrone, B., Brady, D. W., and Cogan, J. F. (2002). Out of step, out of office: Electoral accountability and house members' voting. American Political Science Review, 96(01):127-140.

Carlin, R. E., Singer, M. M., and Zechmeister, E. J. (2015). The Latin American Voter: Pursuing Representation and Accountability in Challenging Contexts. University of Michigan Press.

Carroll, R. and Kubo, H. (2018). Explaining citizen perceptions of party ideological positions: The mediating role of political contexts. Electoral Studies, 51:14-23.

Carroll, R. and Poole, K. (2014). Roll call analysis and the study of legislatures. The Oxford handbook of legislative studies, pages 103-124.

Clark, M. and Leiter, D. (2014). Does the ideological dispersion of parties mediate the electoral impact of valence? a cross-national study of party support in nine western european democracies. Comparative Political Studies, 47(2):171-202.

Clinton, J. D. (2006). Representation in Congress: constituents and roll calls in the 106th House. The Journal of Politics, 68(2):397-409.

Conover, P. J. and Feldman, S. (1981). The origins and meaning of liberal/conservative self-identifications. American Journal of Political Science, pages 617-645.

Converse, P. (1964). E. 1964."the nature of belief systems in mass publics.". Ideology and discontent, pages 206-61.

Curini, L. and Hino, A. (2012). Missing links in party-system polarization: How institutions and voters matter. The Journal of Politics, 74(02):460-473.

Dalton, R. J. (2006). Social modernization and the end of ideology debate: Patterns of ideological polarization. Japanese Journal of Political Science, 7(01):1-22.

Dalton, R. J. (2008). The quantity and the quality of party systems party system polarization, its measurement, and its consequences. Comparative Political Studies, 41(7):899920.

Dalton, R. J. and Anderson, C. J. (2011). Citizens, context, and choice: How context shapes citizens' electoral choices. Oxford University Press.

Dalton, R. J., Farrell, D. M., and McAllister, I. (2011). Political parties and democratic linkage: How parties organize democracy. Oxford University Press. 
Delli Carpini, M. X. and Keeter, S. (1996). What Americans Know about Politics and Why It Matters. Yale University Press.

Dow, J. K. (2011). Party-system extremism in majoritarian and proportional electoral systems. British Journal of Political Science, 41(02):341-361.

Ellis, C. and Stimson, J. A. (2009). Symbolic ideology in the american electorate. Electoral Studies, 28(3):388-402.

Ellis, C. and Stimson, J. A. (2012). Ideology in America. Cambridge University Press.

Ensley, M. J. (2007). Candidate divergence, ideology, and vote choice in US Senate elections. American Politics Research, 35(1):103-122.

Ezrow, L. (2008). Parties' policy programmes and the dog that didn't bark: No evidence that proportional systems promote extreme party positioning. British Journal of Political Science, 38(3):479.

Feldman, S. (1988). Structure and consistency in public opinion: The role of core beliefs and values. American Journal of Political Science, pages 416-440.

Ferland, B. (2018). Ideological congruence over government mandates under majoritarian and proportional representation electoral systems. West European Politics, 41(2):350383.

Fiorina, M. P. and Levendusky, M. S. (2006). Disconnected: The political class versus the people. Red and blue nation, 1:49-71.

Fuchs, D. and Klingemann, H.-D. (1989). Das links-rechts-schema als politischer code. ein interkultureller vergleich auf inhaltsanalytischer grundlage. Kultur und Gesellschaft. Verhandlungen des, 24:484-498.

Gerber, E. R. and Lewis, J. B. (2004). Beyond the median: Voter preferences, district heterogeneity, and political representation. Journal of Political Economy, 112(6):13641383.

Golder, M. and Ferland, B. (2017). Electoral Rules and Citizen-Elite Ideological Congruence. Oxford University Press Oxford.

Gordon, S. B. and Segura, G. M. (1997). Cross-national variation in the political sophistication of individuals: Capability or choice? The Journal of Politics, 59(01):126-147.

Goren, P. (2004). Political sophistication and policy reasoning: A reconsideration. American Journal of Political Science, 48(3):462-478.

Hare, C., Armstrong, D. A., Bakker, R., Carroll, R., and Poole, K. T. (2015). Using bayesian aldrich-mckelvey scaling to study citizens' ideological preferences and perceptions. American Journal of Political Science, 59(3):759-774. 
Hetherington, M. J. (2001). Resurgent mass partisanship: The role of elite polarization. American Political Science Review, 95(3):619-631.

Highton, B. (2009). Revisiting the relationship between educational attainment and political sophistication. The Journal of Politics, 71(04):1564-1576.

Hill, S. J. and Tausanovitch, C. (2015). A disconnect in representation? Comparison of trends in congressional and public polarization. The Journal of Politics, 77(4):10581075 .

Huber, J. and Inglehart, R. (1995). Expert interpretations of party space and party locations in 42 societies. Party politics, 1(1):73-111.

Huber, J. D. and Powell, G. B. (1994). Congruence between citizens and policymakers in two visions of liberal democracy. World Politics, 46(03):291-326.

Jessee, S. A. (2010). Partisan bias, political information and spatial voting in the 2008 presidential election. The Journal of Politics, 72(2):327-340.

Klingemann, H.-D. (2009). The Comparative Study of Electoral Systems. Oxford University Press.

Klingemann, H.-D., Gancheva, D., and Wessels, B. (2017). Ideological Congruence: Choice, Visibility and Clarity. In Harfst, P., Kubbe, I., and Poguntke, T., editors, Parties, Governments and Elites, pages 53-72. Springer Fachmedien Wiesbaden, Wiesbaden. DOI: 10.1007/978-3-658-17446-0_4.

Knutsen, O. (1995). Value orientations, political conflicts and left-right identification: A comparative study. European journal of political research, 28(1):63-93.

Knutsen, O. (1998). The Strength of the Partisan Component of Left-Right Identity A Comparative Longitudinal Study of Left-Right Party Polarization in Eight West European Countries. Party Politics, 4(1):5-31.

Knutsen, O. and Kumlin, S. (2005). The European Voter: A Comparative Study of Modern Democracies. Oxford University Press chapter Value orientations and party choice.

Kroh, M. (2009). The Ease of Ideological Voting: Voter Sophistication and Party System Complexity. The Comparative Study of Electoral Systems.

Lachat, R. (2008). The impact of party polarization on ideological voting. Electoral Studies, 27(4):687-698.

Lau, R. R. and Redlawsk, D. P. (2001). Advantages and disadvantages of cognitive heuristics in political decision making. American Journal of Political Science, pages 951-971.

Lee, F. E. (2015). How party polarization affects governance. Annual review of political science, 18:261-282. 
Levendusky, M. S. (2010). Clearer cues, more consistent voters: A benefit of elite polarization. Political Behavior, 32(1):111-131.

Lewis, J. B. and Tausanovitch, C. (2015). When Does Joint Scaling Allow for Direct Comparisons of Preferences? In Conference on Ideal Point Models, Massachusetts Institute of Technology, Cambridge, MA, May, volume 1.

Lo, J., Proksch, S.-O., and Gschwend, T. (2014). A common left-right scale for voters and parties in europe. Political Analysis, 22(2):205-223.

Lupia, A. and McCubbins, M. D. (1998). The Democratic Dilemma: Can Citizens Learn What They Need to Know? Cambridge University Press.

Lupu, N. (2014). Party polarization and mass partisanship: A comparative perspective. Political Behavior, pages 1-26.

Luskin, R. C. (1987). Measuring political sophistication. American Journal of Political Science, pages 856-899.

Luskin, R. C. (1990). Explaining political sophistication. Political Behavior, 12(4):331361.

Mann, T. E. and Ornstein, N. J. (2013). Finding the Common Good in an Era of Dysfunctional Governance. Daedalus, 142(2):15-24.

Maoz, Z. and Somer-Topcu, Z. (2010). Political polarization and cabinet stability in multiparty systems: A social networks analysis of European parliaments, 1945-98. British Journal of Political Science, 40(4):805-833.

McCarty, N., Poole, K. T., and Rosenthal, H. (2006). Polarized America: The dance of ideology and unequal riches. The MIT Press.

Merrill, S. and Grofman, B. (1999). A unified theory of voting: Directional and proximity spatial models. Cambridge University Press.

Miller, W. E. and Stokes, D. E. (1963). Constituency influence in congress. American political science review, $57(01): 45-56$.

Mondak, J. J. (1999). Reconsidering the measurement of political knowledge. Political Analysis, 8(1):57-82.

Neuman, W. R. (1986). The paradox of mass politics: Knowledge and opinion in the American electorate. Harvard University Press.

Palfrey, T. R. and Poole, K. T. (1987). The relationship between information, ideology, and voting behavior. American Journal of Political Science, pages 511-530.

Pardos-Prado, S. and Dinas, E. (2010). Systemic polarisation and spatial voting. European Journal of Political Research, 49(6):759-786. 
Poole, K., Lewis, J., Rosenthal, H., Lo, J., Carroll, R., et al. (2016). Recovering a basic space from issue scales in r. Journal of Statistical Software, 69(i07).

Poole, K., Rosenthal, H., Lo, J., Carroll, R., and Lo, M. J. (2013). Package 'basicspace'.

Poole, K. T. (1998). Recovering a basic space from a set of issue scales. American Journal of Political Science, pages 954-993.

Poole, K. T. (2005). Spatial models of parliamentary voting. Cambridge University Press.

Poole, K. T. and Rosenthal, H. (1997). Congress: A political-economic history of roll call voting. Oxford University Press.

Poole, K. T. and Rosenthal, H. L. (2011). Ideology and congress, volume 1. Transaction Publishers.

Popkin, S. L. (1994). The Reasoning Voter: Communication and Persuasion in Presidential Campaigns. University of Chicago Press.

Powell, G. B. (2000). Elections as Instruments of Democracy: Majoritarian and Proportional Visions. Yale University Press.

Powell, G. B. (2011). Party polarization and the ideological congruence of governments. In Dalton, Russell J and Anderson, Christopher J, editors, Citizens, context, and choice: How context shapes citizens' electoral choices, pages 197-213. Oxford University Press.

Rehm, P. and Reilly, T. (2010). United we stand: Constituency homogeneity and comparative party polarization. Electoral Studies, 29(1):40-53.

Rogers, S. (2017). Electoral accountability for state legislative roll calls and ideological representation. American Political Science Review, 111(3):555-571.

Saiegh, S. M. (2015). Using joint scaling methods to study ideology and representation: Evidence from latin america. Political Analysis, page mpv008.

Tausanovitch, C. and Warshaw, C. (2013). Measuring constituent policy preferences in congress, state legislatures, and cities. The Journal of Politics, 75(2):330-342.

Tausanovitch, C. and Warshaw, C. (2014). Do legislator positions affect constituent voting decisions in US House elections? Unpublished paper. University of California, Los Angeles, and Massachusetts Institute of Technology, Cambridge, Mass.

Thomassen, J. (2005). The European voter: a comparative study of modern democracies. Oxford University Press on Demand. 


\section{A Appendix}

\section{A.1 Issue Questions from EES and CHES}

Table 3: Survey Items about Policy Questions in EES 2014

\begin{tabular}{l} 
Question \\
\hline QPP17.1 State regulation and control of the market \\
$0=$ You are fully in favour of state intervention in the economy \\
$10=$ You are fully opposed to state intervention in the economy \\
QPP17.2 Redistribution of wealth \\
$0=$ You are fully in favour of the redistribution of wealth \\
from the rich to the poor in the COUNTRY \\
$10=$ You are fully opposed to the redistribution of wealth \\
from the rich to the poor in the COUNTRY \\
QPP17.3 Spending \\
$0=$ You are fully in favour of raising taxes to increase public services \\
$10=$ You are fully in favour of cutting public services to cut taxes \\
QPP17.5 Civil liberties \\
$0=$ You fully support privacy rights even if they hinder efforts to combat crime \\
$10=$ You are fully in favour of restricting privacy rights in order to combat \\
QPP17.6 Immigration \\
$0=$ You are fully in favour of a restrictive policy on immigration \\
$10=$ You are fully opposed to a restrictive policy on immigration \\
QPP17.7 EU integration \\
$0=$ The EU should have more authority over the EU Member States' economic \\
and budgetary policies \\
$10=$ The COUNTRY should retain full control over its economic \\
and budgetary policies \\
QPP17.8 Environment \\
$0=$ Environmental protection should always take priority \\
even at the cost of economic growth \\
$10=$ Economic growth should always take priority \\
even at the cost of environmental protection
\end{tabular}


Table 4: Survey Items about Policy Dimensions in CHES 2014

\footnotetext{
Question

ECON_INTERVEN $=$ position on state intervention in the economy.

$0=$ Fully in favor of state intervention :

$10=$ Fully opposed to state intervention

REDISTRIBUTION $=$ position on redistribution of wealth from the rich to the poor.

$0=$ Fully in favor of redistribution :

$10=$ Fully opposed to redistribution

SPENDVTAX $=$ position on improving public services vs. reducing taxes.

$0=$ Fully in favour of raising taxes to increase public services :

$10=$ Fully in favour of cutting public services to cut taxes.

CIVLIB_LAWORDER $=$ position on civil liberties vs. law and order.

$0=$ Strongly promotes civil liberties :

$10=$ Strongly supports tough measures to fight crime

IMMIGRATE_POLICY $=$ position on immigration policy.

$0=$ Fully opposed to a restrictive policy on immigration :

$10=$ Fully in favor of a restrictive policy on immigration

EU_POSITION $=$ overall orientation of the party leadership towards

European integration (recoded from 7-point and reversed).

$1=$ Strongly favors :

$10=$ Strongly opposes

ENVIRONMENT $=$ position towards the environment.

$0=$ Strongly supports environmental protection even at the cost of economic growth :

$10=$ Strongly supports economic growth even at the cost of environmental protection
} 


\section{A.2 Validity of Ideology Measures}

We examine the face validity of both forms of voter ideal points by comparing them with CHES expert survey "left-right" locations for the parties they support. To do so, we regress each measure on the CHES expert placement locations for "left-right" (LRGEN), which were grouped into ten categorical values by rounding to integers. We simply use a linear regression of these separate categorical values on each measure, pooling across countries. This approach allows us to see the non-linearities that exist in the relationship. We then generate the predicted values from this regression, as well as 95 percent confidence intervals for these values, and plot them below. The results for the latent ideology measure are shown on the left side of Figure 4. Note that there is a rough correspondence between voters' averages and the the party expert scores on the left-right scale, although the rank is not strictly maintained. For comparison, we examine the face validity of the bias-corrected left-right perceptions by the same approach, shown on the right side of Figure 4. Again, the average voters within each ideological category show a general correspondence with the rank order of those parties.
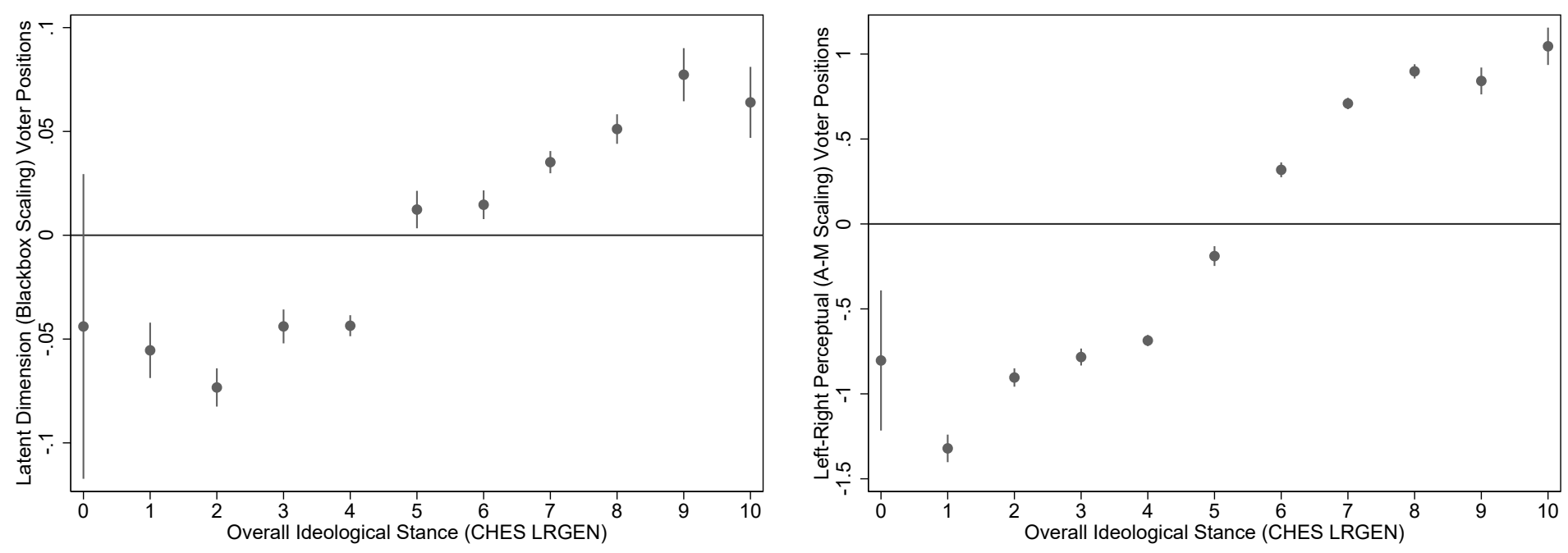

Figure 4: The Relationship Between CHES Expert "Left-Right" and the Voters Ideal Points using Latent Ideological measure (left side) and Perceptual Left-Right Measure 